
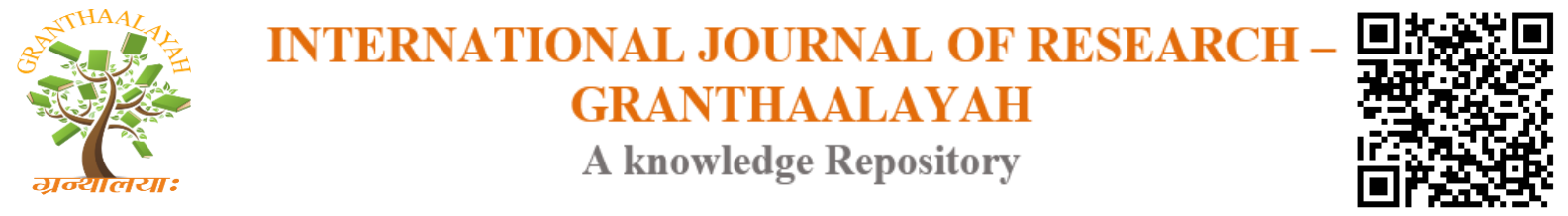

Science

\title{
RELATIONSHIP BETWEEN FAST FOOD CONSUMPTION AND HEALTH OF LATE CHILDHOOD
}

\author{
Dr. Nirmal Kaur ${ }^{* 1}$, Miss Neha Qumar ${ }^{* 2}$, Shubhi Agarwal ${ }^{3}$ \\ ${ }^{* 1}$ Assistant professor, Pushp Institute of Sciences \& Higher Studies, Pilibhit, Uttara Pradesh, \\ INDIA \\ ${ }^{* 2}$ Lecturer, Pushp Institute of Sciences \& Higher Studies, Pilibhit, Uttara Pradesh, INDIA \\ ${ }^{3}$ M.Sc Student, Pushp Institute of Sciences \& Higher Studies, Pilibhit, INDIA
}

DOI: https://doi.org/10.29121/granthaalayah.v4.i6.2016.2640

\section{ABSTRACT}

Eat healthy and live healthy is one of the essential requirements for long life. Unfortunately, today's world has been adapted to a system of consumption of foods which has several adverse effects on health. Lifestyle changes has compelled us so much that one has so little time to really think what we are eating is right or not. Globalization and urbanization have greatly affected one's eating habits and forced many people to consume fancy and high calorie fast foods, popularly known as Junk foods. Diseases like stunted growth and obesity, constipation etc. have seen a profound rise in developing countries and such unhealthy junk food consumption is one of the notable factors to its contribution. This global problem of consuming junk food on a large scale and its impact on health that needs emphasis on health education which can greatly contribute to its limited consumption and switching over to healthy eating habits for the better living. By keeping in mind the following problems associated with fast food consumption the present study was conducted with the objectives i.e. to study the food habits of target group, as well as to study the health problems among target group. The result showed that cent per cent respondents consumed wafers and 93 percent, 90 percent and 86 percent used to have momo's burger and spring roll and the frequency was thrice and twice a week respectively. That is why it was seen that due to the food consumption pattern the respondents were having less height as per their age (96 per cent) having the problem of obesity (93 per cent) constipation (86 per cent) abdominal Pain (83 per cent) and acidity (73 per cent).

Keywords:

Fast food, Junk Food, Health Problems, eating habits, Diseases, Micro-nutrients.

Cite This Article: Dr. Nirmal Kaur, Miss Neha Qumar, and Shubhi Agarwal, "RELATIONSHIP BETWEEN FAST FOOD CONSUMPTION AND HEALTH OF LATE CHILDHOOD” International Journal of Research - Granthaalayah, Vol. 4, No. 6 (2016): 72-81. 


\section{INTRODUCTION}

Children develop at various rates. Some children in late childhood seem to be very mature while other seems very immature. During this stage, behavior may depend on the child's mood, his or her experience with various types of people, or even what happened that day. When they start school, children enter "LATE CHILDHOOD". Between the ages of 6-12years, the child's world expands outward from the family as relationships are formed with friends, teachers and others. The late childhood period is a time to prepare for adolescence [1] childhood has the right to life, survival and development. Essential to this right is the opportunity to live a healthy lifestyle and to develop healthily.

A combination of a nutritious diet, physical activity and the maintenance of a healthy body weight will support children in achieving their personal potential and living long and good quality lives. But this time children attract towards fast foods. Children are more prone to developing unhealthy dietary habits as now a day that are they now eat pizza, soda, burger, spring roll, chowmein, momos and so many snacks which are not good for children's health [2]. The study found out the local children's appetite for fast food. Children are scoffing more fast food a week than even other children who are infamous for their fast food lifestyles. The nonnutritious foods consumed by children, such as hamburgers, pizza, confectionary and soft drinks are precisely those that are promoted heavily during children's TV viewing time [3].

Healthy nutritious foods have been replaced by the new food mantra- i.e. "fast food" In the context of world economy, junk food/fast food is a global phenomenon [4]. Junk/fast food simple means an empty calorie food. An empty calorie food is a high calorie food having high calorie or calorie rich food which lacks in micro-nutrients such as vitamins, minerals or amino acids and fiber but has high energy. These foods don't contain the nutrients that your body needs to stay healthy. Hence, these foods that has poor nutritional value is considered unhealthy and may be called as "FAST FOOD" [5].

Children attracts more towards the fast food, there are some factors which is time factor, taste factor, great taste also, is another important reason to an extent that influences to opt for junk/fast food. Packing of such foods has very attractive appearance by adding food additives and color [6]. Wafers, chips, colas, pizzas and burgers are suddenly the most attractive food items among children which leads too many incurable diseases.

Studies reveals, the beginning of clogging of arteries as early as at the age of 30, risks of prostate and breast cancer linked to their eating habits at puberty, setting of hypertension and osteoporosis at an early age, vulnerability to slow growth, tooth decay, and obesity [7]. Experts warn that eating too much fast food is one of the factors that have contributed to current childhood obesity epidemic. Since fast food and children have a strange affinity to each other, try to avoid children to get habituated to such foods. We can keep good food nearby and having right meals on time certainly helps in this direction. Developing awareness for fitness among children will certainly separate fast food and good diet. We have to build up a fruit and vegetable 
environment around children. We have to seek the child that eating a healthy diet is a hard work, and include pulses, cereals, and vegetables in children's diet [8].

The only way to avoid fast food is to encourage eating healthy snacks and more of this food which are low in fat, saturated fat and cholesterol, high fiber foods, including whole grain foods, calcium rich foods, iron rich foods and foods that have only a moderate amount of sugar and salt [9].

\section{MATERIAL AND METHODS}

\subsection{CONSTRUCTION OF TOOL}

A preliminary survey was conducted in Pilibhit district to develop a rapport with children and become aware with their problems faced by them by asking informal questions. The interview schedule was consisted of several types of questions like; name, age, sex, food habit, health problems etc. and what are the effect of fast food consumption on late childhood.

\subsection{SELECTION OF SAMPLES}

Multistage purposive sampling design was used to select the study area and respondents. The stage included selection of colony and selection of children.

\subsubsection{SELECTION OF LOCALE}

To study the effect of fast food on late childhood, present study was carried out in Pilibhit district of Uttarpradesh. The main reason of selection of this locale was that it was easily approachable for the researcher and total sample size was also available in this area.

\subsubsection{SELECTION OF COLONY}

Altogether three colonies in Pilibhit, were selected purposively for the present study, as required sample size was easily available in these colonies. Hence both male and female children were selected for the study.

\subsubsection{SELECTION OF SAMPLE SIZE}

For the selection of sample an exhaustive list of all the children of selected colonies were prepared, then with the help of random number table altogether total of 30 children were selected from the age group 6-12 age years out of which 17 respondents were male whereas 13 were female.

\subsection{METHOD OF DATA COLLECTION}

The descriptive data was gathered personally by using interview method. Visits were made to the selected colonies prior to data collection to ensure full confidence and co-operation from the respondent. 
For experimental data, the parameters chosen were anthropometric measurements, weight and height of subjects. A brief description of instruments used for this has been given below;

\subsubsection{ANTHROPOMETER}

It is a precision instrument made up of four interconnecting sections of tubular metal that are engraved in millimeter intervals. Current models are capable of measuring stature or other heights from the floor and seated surfaces as well as straights lengths and distances up to 200 cms when completely assembled. The heights were noted by using movable slide that contains an adjustable perpendicular blade, which is placed in alignment with tightened lightly on the desired measuring point.

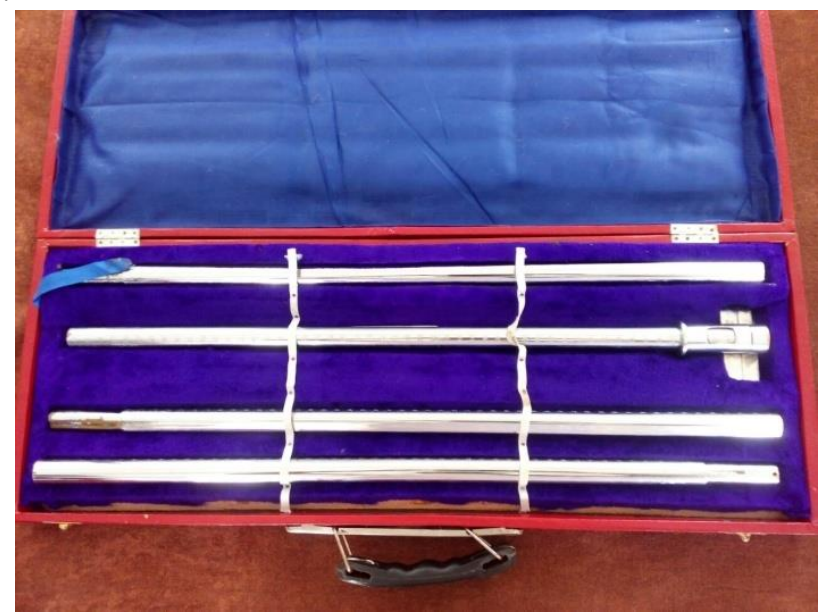

Figure 1: Anthropometric Kit

\subsubsection{WEIGHING BALANCE}

It was used to measure the body weight in kilogram of an individual with minimum clothes and accessories on the body.

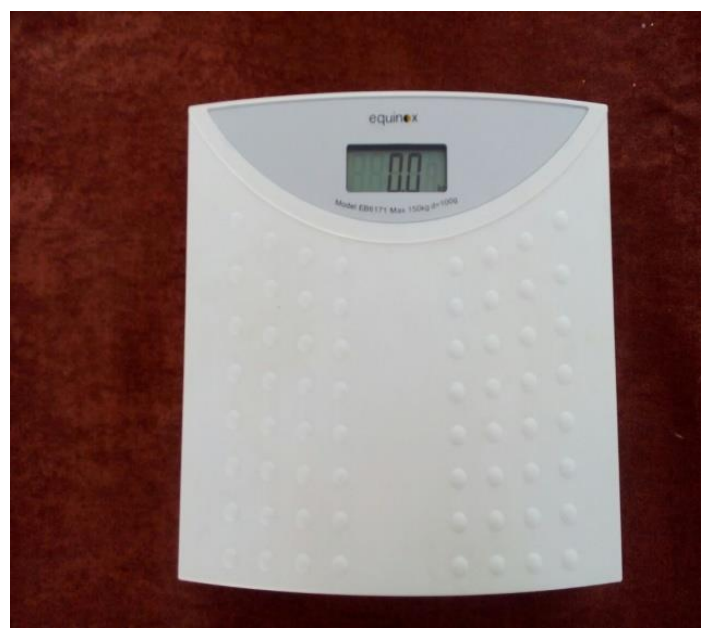

Figure 2: Weighing Balance 


\subsection{VARIABLES UNDER STUDY}

The consumption of fast food of a child is affecting him/her directly or indirectly. Hence in the present study independent and dependent variables were taken as follows.

\subsubsection{INDEPENDENT VARIABLES}

Weight, age, sex, height were considered as Independent variables.

\section{Weight}

The study [10] reported that the weight of the subject is an important factor that should be taken into account, as weight is directly related to muscular stress and fatigue by affecting frequency of body growth. Thus it was taken to measure the weight of the children while seeing the effect of fast food consumption on the children.

\section{Age}

Age was measured in terms of numbers of full years of the respondent completed at the time of interview. It had been taken to find out the effect of fast food consumption on the specific age group of children.

\section{Sex}

Sex was studied as number of male and female children considered for the study. There were differences in the body composition of male and female.

\section{Height}

\subsubsection{DEPENDENT VARIABLES}

Body type and health problems were considered as dependent variables.

I Body Type- Based on Quetelet Index / Ponderal Index, respondents can be divided into different body type i.e. whether the person is of an ectomorph, mesomorph or endomorph category.

Endomorph- The whole figure tends to be round and flabby and has an infantile look because of excess fat storage.

Mesomorph- The body appears to be rectangular, bilaterally well balanced and firm body. It has normal fat content and equal amount of muscles and bones.

Ectomorph- The full body appears to be skinny, lean and thin, fragile and weak.

II Health Problems- A state in which you are unable to function normally and without pain.

a. Over weight- According to WHO Over weight is defined as a BMI greater than or equal to 25 is overweight. 
b. Constipation- It is an acute or chronic condition in which bowel movement occur less often than usual or consist of hard, dry stools that are painful or difficult to pass.

c. Abdominal Pain- It is a pain that you feel anywhere between your chest and groin. This is often referred to as the stomach region or belly.

d. Acidity- The degree of sourness, sharpness of taste, or ability of a chemical to yield hydrogen ions in an aqueous solution.

\subsection{ANALYSIS OF DATA}

The collected data were tabulated and analyzed with the help of subjective statistics and relational statistics. For the purpose of analysis, variables, of the study were categorized as follows:

\subsubsection{EXPERIMENTAL TEST}

To calculate the body type, the following formulas were used in this study

\section{a) Quetlet Index-}

$$
\frac{\text { weight }(\mathrm{kg})}{\text { height }^{2}(\text { meter })}
$$

\section{Scale of Quetlet Index-}

Ectomarph $<20$

Mesomarph 20-25

Endomarph $>25$

b) Ponderal index-

$$
\frac{3 \sqrt{\text { weight }(\mathrm{kg}) \times 100}}{\text { height }(\mathrm{cm})}
$$

\section{Scale of Ponderal Index}

Ectomarph $<21.5$

Mesomarph 21.5-25

Endomarph $>25$

\subsubsection{DESCRIPTIVE STATISTICS}

The data were presented in frequencies, percentage as per analysis of the following information. 


\section{RESULT AND DISCUSSION}

Data shown in table-1 depicts that wafers were the most preferred item consumed by cent per cent of the respondents followed by momo's, burger, spring roll, pizza, tin packed food and chowmin as 93.33 per cent, 90 per cent, 86.66 per cent, 83.33 per cent ,76.66 per cent and 73.33 per cent respectively. Besides this the frequency of consumption was also checked and it was found that wafers were the most frequently consumed items as it was consumed daily by the respondents followed by chowmein as consumed four times in a week and burger tin packed food and momo's thrice a week and spring roll and pizza twice a week.

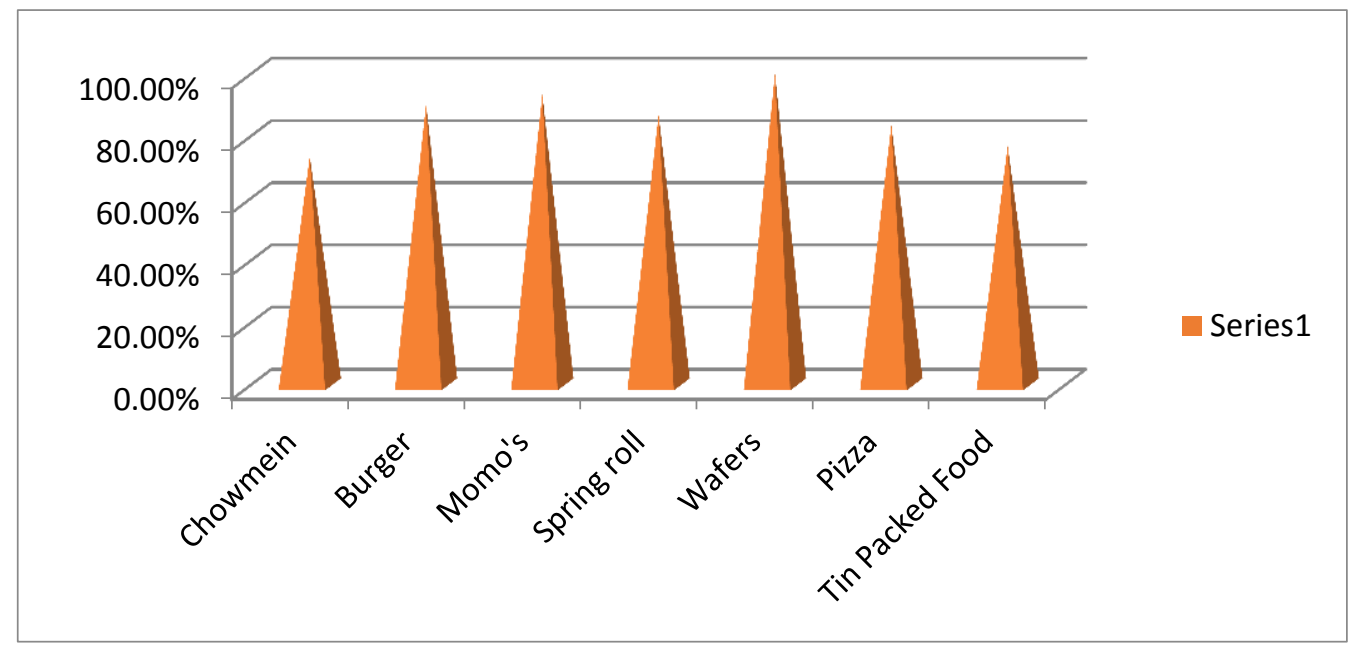

Figure 3: Fast foof consumption pattern

Table 1: FAST FOOD CONSUMPTION AMONG THE RESPONDENTS

\begin{tabular}{|c|c|c|c|c|}
\hline S.No & \multicolumn{2}{|r|}{ CATEGORY } & FREQUENCY & PERCENT \\
\hline \multirow{7}{*}{1.} & \multirow{7}{*}{$\begin{array}{l}\text { Types of fast } \\
\text { food consume }\end{array}$} & Chowmein & 22 & 73.33 \\
\hline & & Burger & 27 & 90 \\
\hline & & Momo & 28 & 93.33 \\
\hline & & Spring roll & 26 & 86.66 \\
\hline & & Wafers & 30 & 100 \\
\hline & & Pizza & 25 & 83.33 \\
\hline & & Tin packed food & 23 & 76.66 \\
\hline \multirow[t]{7}{*}{2.} & \multirow{7}{*}{$\begin{array}{l}\text { Frequency of } \\
\text { consumption } \\
\text { of fast food }\end{array}$} & Chowmein & \multicolumn{2}{|l|}{ Four times a week } \\
\hline & & Burger & \multicolumn{2}{|l|}{ Thrice a week } \\
\hline & & Momo & \multicolumn{2}{|l|}{ Thrice a week } \\
\hline & & Spring roll & \multicolumn{2}{|l|}{ Twice a week } \\
\hline & & Wafers & \multicolumn{2}{|l|}{ Daily } \\
\hline & & Pizza & \multicolumn{2}{|l|}{ Twice a week } \\
\hline & & Tin packed food & \multicolumn{2}{|l|}{ Thrice a week } \\
\hline
\end{tabular}


Table 2: Assessment of body types of respondent's percent and percent

\begin{tabular}{|c|c|c|c|c|c|c|c|c|c|c|c|c|c|}
\hline \multirow[t]{4}{*}{ S.No. } & \multirow[t]{4}{*}{ Sex } & \multicolumn{6}{|c|}{ Quetlet Index } & \multicolumn{6}{|c|}{ Ponderal Index } \\
\hline & & \multicolumn{6}{|c|}{ Category } & \multicolumn{6}{|c|}{ Category } \\
\hline & & \multicolumn{2}{|c|}{ Ectomorph } & \multicolumn{2}{|c|}{ Mesomorph } & \multicolumn{2}{|c|}{ Endomorph } & \multicolumn{2}{|c|}{ Ectomorph } & \multicolumn{2}{|c|}{ Mesomorph } & \multicolumn{2}{|c|}{ Endomorph } \\
\hline & & $\bar{F}$ & $\%$ & $\mathrm{~F}$ & $\%$ & $\mathrm{~F}$ & $\%$ & $\mathrm{~F}$ & $\%$ & $\mathrm{~F}$ & $\%$ & $\mathrm{~F}$ & $\%$ \\
\hline 1 & Male & 3 & 17.6 & 4 & 23.5 & 10 & 58.8 & 2 & 11.7 & 3 & 17.6 & 12 & 70.5 \\
\hline 2 & Female & 1 & 7.6 & 1 & 7.6 & 11 & 84.6 & 1 & 7.6 & 2 & 15.3 & 10 & 76.9 \\
\hline
\end{tabular}

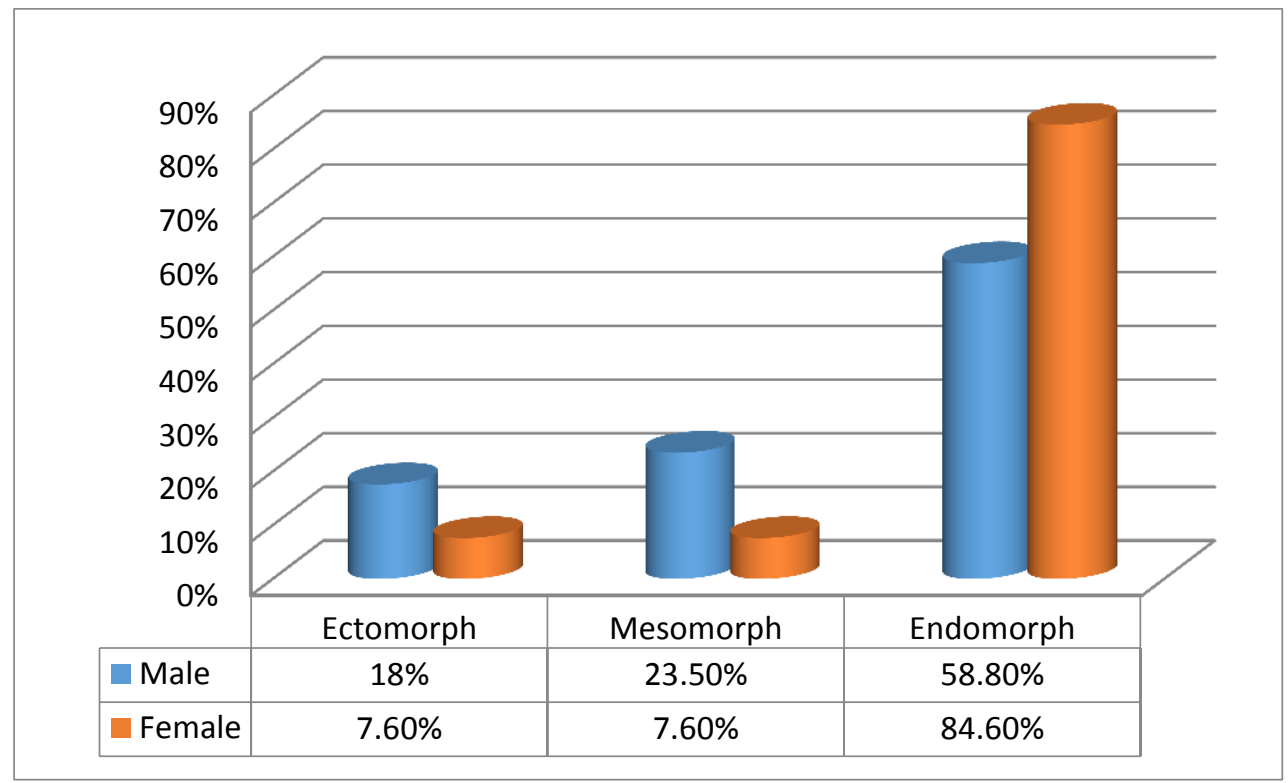

Figure 4: Body type of respondent as per Quetlet Index

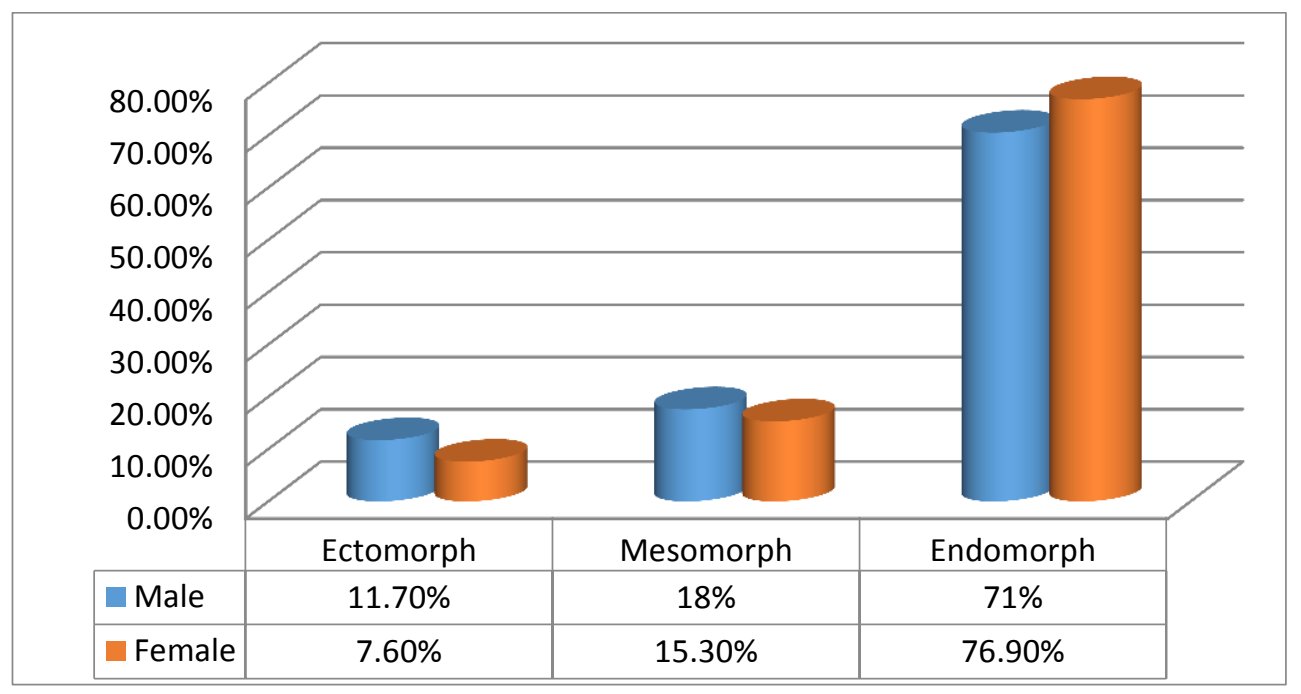

Figure 5: Body type of respondent as per Ponderal Index 
It can be invisaged from Table-2 that out of 17 male and 13 female respondent maximum were found endomorph i.e.58.8 percent and 84.6 per cent respectively as per the calculation or Quetlet Index and on the basis of Ponderal Index also the maximum number of respondents of both the sexes were found in the category of endomorph i.e. 70.5 per cent male and 76.9 per cent female as shown in Figure 4 and 5.

\section{Table 3: COMPLICATIONS FACED BY CHILDREN}

\begin{tabular}{|c|c|c|c|c|}
\hline S.No & \multicolumn{2}{|c|}{ CATEGORY } & FREQUENCY & PERCENT \\
\hline \multirow{4}{*}{1.} & \multirow{4}{*}{ Complications } & Constipation & 26 & 86.66 \\
\hline & & Abdominal Pain & 25 & 83.33 \\
\hline & & Acidity & 22 & 73.33 \\
\hline & & Over weight & 28 & 93.33 \\
\hline
\end{tabular}

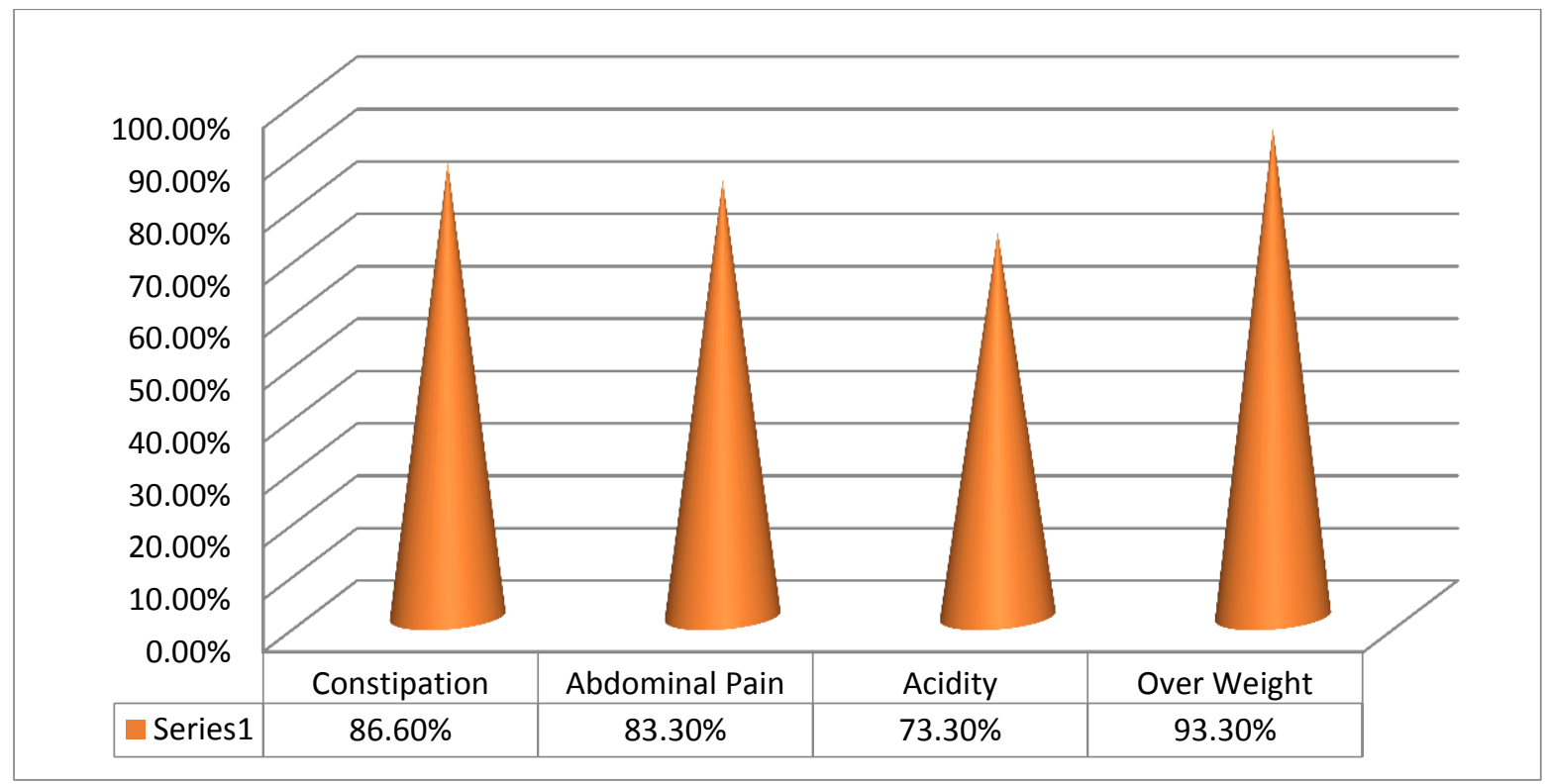

Figure 6: Complications Faced by the Respondents

When it was tried to find out about the complications amongst the respondents consuming fast food then the most common health problem was found as over weight (93.33 per cent) followed by constipation ( 86.66 per cent) abdominal pain ( 83.33 per cent) and acidity (73.33 per cent) as shown in Figure 6.

\section{CONCLUSION}

Children attracts more towards the fast food, there are various factors responsible for it and amongst all time factor is the most common , and taste factor is another important reason to an extent that influences to opt for junk/fast food. Wafers, chips, colas, pizzas and burgers are suddenly the most attractive food item. Children, especially young children, are more vulnerable to the environment and easily attracted by an unhealthy diet pattern once they have established 
these unhealthy dietary patterns during their early years, it is hard to correct in later life. Changing lifestyle and work habits are the main two major factors deciding consumer preference for fast food that is driving them towards junk health. Fast food can affect a child's physical development in detrimental ways, including unhealthy weight gain, which can result in selfesteem problems whereas some fast food meals give the child, a whole days worth of calories. That can really pack on the pounds. Being overweight is a risk factor for a variety of chronic health problems also.

\section{REFERENCES}

[1] Kohlberg, L. (1969). "Stage and sequence: The cognitive approach to socialization." In D.A. Goslin (Ed.), Handbook of Socialization Theory and Research. Chicago: Rand McNally.

[2] Finucane FM, Teong L, Pittock S, Fallon M, Hatunic M, Costigan C, et al. 2008 Mar. Adverse metabolic profiles in a cohort of obese Irish children. Ann Clin Biochem; 45(Pt 2):206-9.

[3] Naaidoo.S, 12 October 2008, “Killer Food”, Sunday times, p5.

[4] Holmboe-Ottesen G. Global trends in food consumption and nutrition. Tidsskr

[5] Nor Laegeforen 2000; 120:78-82.

[6] Ashakiran \& Deepthi $R$ Department of Biochemistry, 2Department of Community Medicine, Sri Devaraj Urs Medical College, (Karnataka), India Fast Foods and their Impact on Health Journal of Krishna Institute of Medical Sciences University Vol. 1, No. 2, July-Dec. 2012

[7] Dixon HG, Scully ML, Wakefield MA, White VM, Crawford DA. The effects of television advertisements for junk food versus nutritious food on children.s food attitudes and preferences. Soc Sci Med 2007; 65:1311-23

[8] Jackson P, Romo MM, Castillo MA, Castillo-Durán C. Junk food consumption and child nutrition. Nutritional anthropological analysis. Rev Med Chil 2004; 132:1235- 42.

[9] Panunzio MF, Antoniciello A, Ugolini G, Dalton S. Bring fruit at school: promotion of healthy food habit in primary school-children. Ann Ig 2009; 2:403-7.

[10] Pérez Rodrigo C, Aranceta J, Brug H, Wind M, Hildonen Ch, Klepp KI. School-based education strategies to promote fruit and vegetable consumption: the Pro Children Project Arch Latinoam Nutr 2004; 54:14-9.

[11] Grover $R$ (2002). Sutability of Ergonomically Designed Table and chair for physically Challenged children. 